\title{
Bigger Males, Bigger Females? Pigeons' Sexual Size Dimorphism
}

\author{
P. M. Parés-Casanova ${ }^{1^{*}}$ and A. Kabir ${ }^{2}$ \\ ${ }^{1}$ Department of Animal Science, ETSEA, University of Lleida, Av. Rovira Roure 191, \\ 25198 Lleida, Catalonia, Spain. \\ ${ }^{2}$ Department of Biology, Saidpur Cantonment Public College, Nilphamari, Bangladesh.
}

\begin{abstract}
Authors' contributions
This work was carried out in collaboration between both authors. Both authors interpreted the data, critically revised the manuscript for important intellectual contents and approved the final version. Both authors read and approved the final manuscript.
\end{abstract}

Article Information

DOI: 10.9734/ARRB/2020/v35i1030286

Editor(s):

(1) Dr. Moacir Marocolo, Federal University of Juiz de Fora, Brazil.

Reviewers:

(1) Maria Cristina Oddone, Universidade Federal do Rio Grande, Brazil. (2) S. Upendhar, Jayashankar Telangana State Agricultural University, India. Complete Peer review History: http://www.sdiarticle4.com/review-history/61480

Original Research Article

Received 18 July 2020

Accepted 23 September 2020

Published 08 October 2020

\begin{abstract}
Sexual dimorphism, defined as phenotypic differences between males and females, is a common phenomenon in animals. In this line, Rensch's rule states that sexual size dimorphism increases with increasing body size when the male is the larger sex and decreases with increasing average body size when the female is the larger sex. Domesticated animals offer excellent opportunities for testing predictions of functional explanations of Rensch's theory. Pigeon breeds encounters many different functional purposes and selective constraints, which could influence strongly their morphology. The aim of this paper is to examine, for first time, Rensch's rule among domestic pigeons. It was compiled a database of 12 quantitative traits (body weight, body height, beak thickness, beak length, neck length, neck thickness, wing length, rump width, tail length, tarsus length, tarsus thickness and middle toe length) for males and females of 11 different domestic pigeon breeds: Bangladesh Indigenous, Racing Homer, Turkish Tumbler, Indian Lotan, Kokah, Mookee, Indian Fantail, Bokhara Trumpeter, Bombai, Lahore and Hungarian Giant House; Rock Pigeon (Columba livia) was also considered as wild relative for comparative purposes. Comparative results between males and females showed that only body weight, wing length and neck thickness were consistent with Rensch's rule. The rest of trait did not present correlations. Among domestic
\end{abstract}


pigeons, there can appear different expressions of dimorphism according to each trait, so it must be considered that Rensch's rule vary when considering other traits than body weight.

Keywords: Columba livia; dove, monogamous; Rensch's rule; rock pigeon.

\section{INTRODUCTION}

Sexual size dimorphism (SSD), defined as a phenotypic difference between males and females of a species, is a common phenomenon in animals [1] [2]. SSD is widespread and assumes two forms: male-biased SSD, when males are the larger sex, and female-biased SSD, when females are bigger [3]. SSD occurs in most endothermic vertebrates [3]. Rensch's rule states that SSD increases with increasing body size when the male is the larger sex and decreases with increasing average body size when the female is the larger sex $[4,5,3]$ although this rule is far from perfect [6].

Domestic species possess an extraordinary ability to radiate into numerous morphologically and behaviourally distinct breeds within a few generations. Over thousands of years of domestication, pigeons (family Columbidae, which includes also doves and colombes) have been considerably differentiated by natural and artificial selections and the tendency has been to obtain domestic breeds which in some cases differ enormously from the wild ancestor, the Rock Pigeon (Columba livia, J.F. Gmelin, 1789) [2]. Nowadays, there are hundreds of morphologically differentiated pigeon breeds which differ in size, colouring, etc. For instance, differences in weight are very apparent, ranging from 155 to $170 \mathrm{~g}$ for Figureta Valenciana to over 1.4 kilogram for the American Giant Runt [2], [7]. Rock doves range from 238 to $380 \mathrm{~g}$ [8].
The aim of this paper is to test Rensch's rule among domestic breeds of pigeon, as practically no studies have explored till now sexual dimorphism in domestic pigeons [9]. The expectation is that if natural sexual selection has a primary role in generating Rensch's rule, SSD allometry consistent with Rensch's rule will be present in pigeon breeds. This expectation is based on the idea that artificial selection likely will mimic sexual selection for pigeons, the potential driver of Rensch's rule in wild populations, because humans can use nonnatural directional selection to obtain the desired traits such as increased meat production, "beauty" displays or flight performances [2].

\section{MATERIALS AND METHODS}

We compiled a database of male and female quantitative traits for 11 local and exotic pigeon breeds in Bangladesh: Indigenous, Racing Homer, Turkish Tumbler, Indian Lotan, Kokah, Mookee, Indian Fantail, Bokhara Trumpeter, Bombai, Lahore and Hungarian Giant House, and Rock Pigeon (Columba livia) as wild relative. Second author collated data following standard methods [8]. A total of 12 variables were obtained for each breed: body weight, body height, beak thickness, beak length, neck length, neck thickness, wing length, rump width, tail length, tarsus length, tarsus thickness and middle toe length. In table 1 there appear values for body weight and body length for each breed, and in Table 2 for the rest of values.

Table 1. Values (body weight and body length) for each sex in the studied pigeons

\begin{tabular}{lllll}
\hline & $\begin{array}{l}\text { Body } \\
\text { weight } \mathbf{( g )}\end{array}$ & $\begin{array}{l}\text { Body } \\
\text { length } \mathbf{( c m )}\end{array}$ & $\begin{array}{l}\text { Body } \\
\text { weight }(\mathbf{g})\end{array}$ & $\begin{array}{l}\text { Body } \\
\text { length (cm) }\end{array}$ \\
\hline & Male & Male & Female & Female \\
\hline Rock pigeon & 310 & 19.0 & 320 & 22.8 \\
Bokhara Trumpeter & 430 & 22.4 & 400 & 22.4 \\
Bombai & 430 & 21.3 & 350 & 18.2 \\
Hungarian Giant House & 690 & 26.4 & 680 & 26.4 \\
Indian Fantail & 430 & 23.0 & 420 & 21.5 \\
Indian Lotan & 420 & 24.3 & 300 & 20.4 \\
Indigenous & 450 & 24.4 & 350 & 22.5 \\
Kokah & 330 & 13.3 & 310 & 15.0 \\
Lahore & 540 & 24.5 & 410 & 21.8 \\
Mookee & 340 & 19.2 & 300 & 23.4 \\
Racing Homer & 550 & 21.0 & 600 & 23.0 \\
Turkish Tumbler & 280 & 17.7 & 310 & 15.5 \\
\hline
\end{tabular}


Table 2. Values for each trait in the studied pigeons

\begin{tabular}{|c|c|c|c|c|c|c|c|c|c|c|}
\hline & $\begin{array}{l}\text { Bk } \\
\text { Th }\end{array}$ & $\begin{array}{l}\text { Bk } \\
\text { Le }\end{array}$ & $\begin{array}{l}\mathrm{Ne} \\
\mathrm{Th}\end{array}$ & $\begin{array}{l}\mathrm{Ne} \\
\mathrm{Le}\end{array}$ & $\begin{array}{l}\text { Wi } \\
\text { Le }\end{array}$ & $\begin{array}{l}\mathbf{R u} \\
\mathrm{Wi}\end{array}$ & $\begin{array}{l}\mathrm{Ta} \\
\text { Le }\end{array}$ & $\begin{array}{l}\text { Tr } \\
\text { Le }\end{array}$ & $\begin{array}{l}\text { Tr } \\
\text { Th }\end{array}$ & $\begin{array}{l}\text { Mi } \\
\text { Le }\end{array}$ \\
\hline Rock Pigeon $\delta^{\wedge}$ & 1.24 & 2.1 & 4.9 & 4.30 & 22.3 & 5.1 & 11.1 & 2.3 & 0.64 & 3.6 \\
\hline 우 & 1.30 & 2.0 & 3.8 & 3.23 & 21.8 & 4.6 & 10.0 & 2.3 & 0.55 & 3.2 \\
\hline Indigenous $\hat{O}^{\lambda}$ & 1.20 & 2.0 & 4.6 & 4.06 & 23.0 & 6.0 & 11.5 & 3.2 & 0.62 & 4.0 \\
\hline 오 & 1.00 & 2.0 & 4.0 & 3.35 & 20.5 & 4.4 & 9.5 & 2.0 & 0.64 & 3.0 \\
\hline Racing Homer $\hat{o}^{\lambda}$ & 1.65 & 2.4 & 5.0 & 4.14 & 24.4 & 5.5 & 10.5 & 2.6 & 0.74 & 2.6 \\
\hline q & 1.31 & 2.0 & 4.0 & 4.03 & 22.5 & 5.0 & 8.0 & 2.5 & 0.81 & 3.6 \\
\hline Turkish Tumbler $\hat{0}$ & 0.80 & 2.0 & 4.2 & 3.83 & 23.0 & 5.0 & 10.0 & 2.2 & 0.50 & 2.8 \\
\hline 우 & 0.55 & 2.0 & 4.2 & 4.03 & 22.0 & 4.2 & 10.0 & 2.1 & 0.51 & 3.1 \\
\hline Indian Lotan $\widehat{O}^{\pi}$ & 1.15 & 2.1 & 5.0 & 4.23 & 24.2 & 5.0 & 10.2 & 2.2 & 0.66 & 3.6 \\
\hline 우 & 1.14 & 2.0 & 3.5 & 3.35 & 23.3 & 4.6 & 10.2 & 2.4 & 0.52 & 3.4 \\
\hline Kokah ${ }^{\wedge}$ & 0.93 & 2.1 & 3.2 & 3.80 & 21.2 & 4.3 & 8.7 & 2.5 & 0.51 & 3.2 \\
\hline 오 & 0.95 & 1.9 & 4.8 & 3.91 & 21.0 & 5.0 & 9.9 & 2.8 & 0.65 & 3.3 \\
\hline Mookee $\sigma^{\lambda}$ & 1.01 & 1.8 & 3.9 & 4.46 & 22.6 & 4.4 & 11.6 & 2.4 & 0.64 & 3.5 \\
\hline 오 & 1.10 & 1.7 & 4.4 & 3.30 & 23.4 & 5.0 & 11.0 & 2.4 & 0.61 & 2.9 \\
\hline Indian Fantail $\hat{~} \hat{}$ & 1.10 & 1.6 & 6.4 & 4.41 & 26.5 & 6.9 & 14.5 & 2.5 & 0.84 & 3.2 \\
\hline 우 & 1.24 & 1.7 & 6.4 & 4.21 & 25.0 & 6.5 & 13.5 & 2.6 & 0.82 & 3.7 \\
\hline Bokhara Trumpeter $\hat{o}$ & 1.06 & 2.1 & 5.3 & 4.86 & 29.2 & 5.8 & 12.9 & 3.9 & 1.04 & 3.9 \\
\hline q & 1.10 & 2.1 & 4.7 & 3.80 & 28.7 & 5.6 & 12.3 & 2.9 & 0.84 & 3.7 \\
\hline Bombai ${ }^{\lambda}$ & 1.00 & 1.8 & 6.0 & 3.82 & 24.0 & 4.7 & 10.0 & 2.2 & 0.75 & 3.2 \\
\hline 오 & 1.10 & 1.7 & 6.6 & 3.34 & 22.4 & 5.5 & 11.0 & 2.2 & 0.61 & 3.6 \\
\hline Lahore $\hat{0}$ & 1.24 & 2.4 & 5.3 & 4.60 & 27.7 & 6.5 & 12.2 & 2.7 & 1.02 & 3.7 \\
\hline 우 & 1.04 & 2.0 & 5.0 & 4.82 & 25.9 & 5.2 & 12.4 & 3.0 & 0.80 & 3.5 \\
\hline Hungarian Giant House $\hat{~}$ & 1.44 & 2.3 & 6.7 & 5.27 & 35.5 & 7.1 & 17.4 & 2.8 & 0.90 & 3.8 \\
\hline & 1.30 & 2.5 & 4.6 & 5.55 & 32.6 & 6.4 & 16.4 & 2.7 & 1.24 & 3.8 \\
\hline
\end{tabular}

(TrTh) and middle toe length (MiLe)

Size allometries were obtained plotting the logtransformed values of male versus female values for each breed as such plots provide a measure of allometry [10]. If Rensch's rule is accomplished, the slope of regression of $\log 10$ (female) on log10 (male) will be significantly different from 1 [11], [3]. This was test with an ANCOVA test. All analysis were performed with PAST v. 2.17c software [12]. The level for statistical significance was set at $5 \%$.

\section{RESULTS}

In some breeds (Racing Homer and Turkish Tumbler) and Rock Pigeon, males are smaller than females (Tables 1 and 2). The slopes of regressions of $\log _{10}$ (female) on $\log _{10}$ (male) were significantly different from 1 for body weight $(p=0.0342)$ neck thickness $(p=0.0164)$ and wing length $(p=0.000483)$ with hypoallometries for all these three. For these characters, among large breeds, males are smaller than females and they increase with male size, whereas in small breeds, females tend to be equally larger than males and dimorphism decreases with an increase of the trait. For the rest of traits, slopes were significantly not different from 1 , pigeons exhibiting isometry.

\section{DISCUSSION}

Rensch's rule describes the pattern of sexual size dimorphism (SSD) and claims that larger species generally exhibit higher male to female body size ratios [13]. In recent years, this rule has attracted considerable research, and conforming patterns have been reported by interspecific comparisons for various domestic animals, especially or exclusively in taxa exhibiting larger males [5]. But this rule is by no means universal and is particularly lacking in some domestic species. Rensch's rule has been documented in cattle [1], sheep [14], domestic cats and dogs (but not their wild relatives) [15], but not in swine [16] and chickens [17]. The direction of these differences, that is whether males or females are larger, varies from one species to other [16] and to date, the mechanisms producing it remain unclear [17], being the sexual selection hypothesis a mere 
general explanation for SSD allometry [5]. Of several evolutionary hypotheses proposed to explain the origin and maintenance of SSD, the most widely accepted is based upon the theory of sexual selection [18].

Two reasons are proposed for the maintenance of allometry in domestic pigeons for certain size traits (body weight, wing length and neck thickness). First, male-male competition in captivity are not reduced because males are normally housed together. Strong sexual selection for large males leads to, under natural conditions, a large male body size, with a weaker selection for female body mass, which results in SSD allometry consistent with Rensch's rule. Selection for strong, heavy males are thus be conserved, at least indirectly. Second, in the wild, males and females are exposed to natural and sexual selections of different strengths, resulting in different net selection acting on males and females for the same traits which may be either sex-specific (different strengths but the same direction) or sexually antagonistic (different direction). Similarly, humans have used directional selection for pigeons to achieve the desired characteristics in the targeted sex. In domestic pigeon, males and females can differ substantially in the direction and magnitude of trait selection (for instance bigger in males among pouters) where selection is to improve certain traits, according to each breed, where the key factor can be sexual selection related to body size. Finally, it can be supposed that other aspects of selection could also have changed with domestication (resource competition, predators).

We should keep in mind that artificial selection and formation of breeds in domesticated animals is a different process involving for instance different phenetic changes other that size changes, with intended selection or not. In fact, "pigeons have been changed through its colour and structure. It has gained a lot of peculiar characteristics (e.g. tumbling/rolling, tremule, muff, tallness, erect tail, care etc)" [19]. The sexual selection hypothesis that suggests that Rensch's rule is driven by a correlated evolutionary change in female body size to directional sexual selection on increased body size in males [5] had not been followed during the artificial process of pigeon breeds formation. Sexual dimorphism in pigeon breeds is more the result of the breeder actively suppressing or enhancing a trait, functional or not: showiness (Hungarian Giant House, Mookee) rolling (Indian
Lotan, Turkish Tumbler) the speed (Racing Homer), meat production, etc., so the strength of sexual selection among domestic pigeons is variable according to traits.

Future studies should address specific explanations for allometries for each different trait.

\section{CONCLUSION}

Rensch's rule states that in groups of related species, sexual size dimorphism is more pronounced in larger species. This widespread and fundamental allometric relationship appears differently expressed in pigeon breeds, according to each trait.

\section{CONSENT}

The study involved taking body measurements from pigeons with the consent and in the presence of the breeders. The data was collected in fancies and animal owners agreed to be involved in the project. As there is no national specific legislation for body measurements, no approval was necessary.

\section{ACKNOWLEDGEMENTS}

We would like to thank the reviewers for their comments and suggestions for the manuscript.

\section{SIGNIFICANCE STATEMENT}

This study describes that sexual dimorphism in pigeon breeds is more the result of the breeder actively suppressing or enhancing a trait, functional or not, rather than a mere biological response.

\section{COMPETING INTERESTS}

Authors have declared that no competing interests exist.

\section{REFERENCES}

1. Polák J, Frynta D. Patterns of sexual size dimorphism in cattle breeds support Rensch's rule. Evol. Ecol. 2010;24(5): 1255-1266.

DOI: 10.1007/s10682-010-9354-9.

2. Sambraus HH, A Colour Atlas of Livestock Breeds. Stuttgart: Wolfe Publishing Ltd.; 1989. 
3. Bidau CJ, Martinez PA. Sexual size dimorphism and Rensch's rule in Canidae. Biol. J. Linn. Soc. 2016;119:816-830.

4. Owens IPF, Hartley IR. Sexual dimorphism in birds: why are there so many different forms of dimorphism? Proc. R. Soc. B Biol. Sci. 1998;265:397-407.

5. Frynta D, Baudyšová J, Hradcová $P$, Faltusová K, Kratochvíl L. Allometry of Sexual Size Dimorphism in Domestic Dog. PLoS One. 2012;7(9):5-10.

DOI: 10.1371/journal.pone.0046125

6. Björklund M. A phylogenetic interpretation of sexual dimorphism in body size and ornament in relation to mating system in birds. J. Evol. Biol., 2002;3(3-4):171183.

DOI:10.1046/j.1420-9101.1990.3030171.x.

7. Shapiro MD, Domyan ET. Domestic pigeons. Curr. Biol. 2013;23(8):1-5.

DOI: 10.1016/j.cub.2013.01.063

8. Johnston RF. Variation in size and shape in pigeons, Columba livia. Willson Bull. 1990;102(2):213-225.

9. Sándor Piross I, Harnos A, Rózsa L. Rensch's rule in avian lice: contradictory allometric trends for sexual size dimorphism. Sci. Rep. 2019;9(1):1-9.

DOI: $10.1038 / \mathrm{s} 41598-019-44370-5$

10. Dale J, Dunn PO, Figuerola J, Lislevand T, Székely T, Whittingham LA. Sexual selection explains Rensch's rule of allometry for sexual size dimorphism. Proc. R. Soc. B Biol. Sci. 2007;274(1628): 29712979.

DOI: $10.1098 / \mathrm{rspb} .2007 .1043$.
11. Székely T, Freckleton RP, Reynolds JD, Sexual selection explains Rensch's rule of size dimorphism in shorebirds. PNAS. 2004;101(33):12224-12227.

Available:www.pnas.org/cgi/doi/10.1073/p nas.0404503101

12. Hammer $\varnothing$, Harper DAT, Ryan PD. PAST v. 2.17c. Palaeontol. Electron., 2001;4(1): 1-229.

13. Parés-Casanova PM. No ecogeographical trends in body structure for Zebu (Bos indicus). Glob. J. Multidiscip. Appl. Sci. 2013;1-2:37-40.

14. Parés-Casanova PM. Discrete sexual size dimorphism in domestic sheep. Ann. Biol. Res. 2015;6(10):43-48.

15. Bidau CJ, Martínez PA. Cats and dogs cross the line: Domestic breeds follow Rensch's rule, their wild relatives do not. Vavilovskii Zhurnal Genet. Selektsii. 2017; 21(4):443-451.

DOI: 10.18699/VJ17.263.

16. Parés-Casanova PM. Sexual size dimorphism in swine denies Rensch's rule. Asian J. Agric. Food Sci. 2013;1(4):112118.

17. Remeš V, Székely T. Domestic chickens defy Rensch's rule: Sexual size dimorphism in chicken breeds. J. Evol. Biol. 2010;23(12):2754-2759.

DOI: $10.1111 / \mathrm{j} .1420-9101.2010 .02126 . x$

18. Darwin C. La variación en los animales y las plantas domesticados, 2nd Ed. London: John Murray; 1875.

19. Ashraful MK. Expression of the emotions in pigeons. J. Ethol. Anim. Sci. 2019;2(1).

(c) 2020 Parés-Casanova and Kabir; This is an Open Access article distributed under the terms of the Creative Commons Attribution License (http://creativecommons.org/licenses/by/4.0), which permits unrestricted use, distribution, and reproduction in any medium, provided the original work is properly cited.

Peer-review history:

The peer review history for this paper can be accessed here: http://www.sdiarticle4.com/review-history/61480 